\title{
Nano-Hydroxyapatite Coating Promotes Porous Calcium Phosphate Ceramic-Induced Osteogenesis Via BMP/Smad Signaling Pathway
}

This article was published in the following Dove Press journal: International Journal of Nanomedicine

\author{
Jing Wang' \\ Menglu Wang' \\ Fuying Chen' \\ Yihang Wei ${ }^{\text {I }}$ \\ Xuening Chen' \\ Yong Zhou ${ }^{2}$ \\ Xiao Yang' \\ Xiangdong Zhu $\mathbb{D}^{\prime}$ \\ Chongqi Tu $\mathbb{D}^{2}$ \\ Xingdong Zhang' \\ 'National Engineering Research Center \\ for Biomaterials, Sichuan University, \\ Chengdu 610064, People's Republic of \\ China; ${ }^{2}$ Department of Orthopaedics, \\ West China Hospital of Sichuan \\ University, Chengdu 61004I, People's \\ Republic of China
}

Correspondence: Xuening Chen; Xiangdong Zhu

National Engineering Research Center for Biomaterials, Sichuan University, Chengdu 610064, People's Republic of China Email xchen6@scu.edu.cn; zhu_xd1973@scu.edu.cn
Background: The hierarchical porous structure and surface topography of calcium phosphate $(\mathrm{CaP})$ bioceramics have a crucial impact on their osteoinductivity.

Purpose: To fabricate a biomimetic bone graft with an interconnected porous structure analogous to that of trabecular bone and a bioactive nanostructured surface with excellent osteoinductive potential.

Materials and methods: A biphasic $\mathrm{CaP}(\mathrm{BCP})$ substrate with highly porous structure was fabricated by an improved sponge replication method. Surface modification was performed by uniformly depositing a hydroxyapatite (HA) nanoparticle layer to create nHA-coated BCP scaffolds. The effects of these scaffolds on osteogenic differentiation of murine bone marrow-derived stem cells (BMSCs) were investigated in vitro, and their osteoinductivity was further assessed in vivo.

Results: The BCP and nHA-coated BCP scaffolds had similar trabecular bone-like architectures but different surface structures, with mean grain sizes of $\sim 55 \mathrm{~nm}$ and $\sim 1$ $\mu \mathrm{m}$, respectively. Compared with the BCP substrate, the nHA-coated BCP scaffolds favored cell adhesion and promoted osteogenic differentiation of BMSCs, as evidenced by upregulated expression of osteogenic genes, enhanced alkaline phosphatase activity, and increased osteocalcin production. This could be attributed to activation of the BMP/ Smad signaling pathway, as significantly higher expression levels of BMPRI, Smad1, Smad4, and Smad5 were observed in the nHA-coated BCP group. The nHA-coated BCP scaffold not only maintained scaffold integrity but also induced ectopic bone formation when implanted into rabbit dorsal muscle in vivo for 90 days, whereas the BCP substrate underwent marked biodegradation that led to severe inflammation with no sign of osteogenesis.

Conclusion: The present study demonstrates the potential of this biomimetic bone graft with a trabecular framework and nanotopography for use in orthopedic applications.

Keywords: nano-hydroxyapatite, calcium phosphate ceramics, porous scaffolds, MSCs, osteoblastic differentiation, osteoinduction

\section{Introduction}

Calcium phosphate $(\mathrm{CaP})$ bioceramics are of considerable interest in the orthopedic clinic for use as bone graft substitutes. ${ }^{1,2}$ It is well known that the physicochemical properties of $\mathrm{CaP}$ scaffolds influence their functionalities. Our previous studies have demonstrated that an interconnected porous structure is a prerequisite for the osteoinductivity and osteoconductivity of $\mathrm{CaP}$ bioceramics; it is generally believed that macropores $(>100 \mu \mathrm{m})$ facilitate the in-growth of newly 
formed bone and blood vessels, whereas micropores $(0.1-100 \mu \mathrm{m})$ are favorable for cell proliferation and growth. ${ }^{3-5}$ Thus, many techniques have been developed to fabricate porous scaffolds, including 3D printing, gas foaming, and freeze casting. ${ }^{3,6,7}$ The sponge replication method has attracted considerable attention as it can be used to readily make bone substitutes with highly porous structures, uniform pore geometry, and fine interporous connections that resemble the hierarchical structure of trabecular bone. These can be used to provide transportation highways and induce the growth of newly formed bone deep inside the host body. ${ }^{3,8,9}$

Moreover, inspired by its compositional and structural similarity to the inorganic constituent of native bone, nano-sized hydroxyapatite (nHA) has become a research hotspot in the field of bone regeneration. Extensive studies have demonstrated that nHA has excellent bioaffinity and the ability to promote bone integration. ${ }^{10-12}$ For instance, Cai et $\mathrm{al}^{13}$ found that nHA could better upregulate gene expression of type I collagen and promote osteoblastic differentiation of bone marrow-derived mesenchymal stem cells (BMSCs) compared with a micro-sized structure. Recently, a unique phenomenon was discovered in which nHA particles showed suppressive and apoptotic effects on osteosarcoma cells but improved the viability and proliferation of BMSCs; this was believed to be closely related to particle size. ${ }^{14-17}$ These findings suggest that nHA not only induces osteogenesis to repair hard tissue injury but also promotes selective apoptosis of tumor cells. Thus, nHA has emerged as an ideal candidate for biomedical applications. ${ }^{18,19}$ However, it is difficult to endow $\mathrm{CaP}$ ceramics with both an interconnected porous structure and a bioactive nanostructured surface, as grains grow rapidly and pores collapse easily during the sintering process. ${ }^{1}$ Therefore, multiple approaches have been developed to incorporate nHA particles with artificial bone grafts, including the deposition of nHA coating onto a scaffold surface, which provides a simple and effective means to functionalize an implant and improve its hydrophilicity and biocompatibility. ${ }^{20-22}$

The aim of this study was to fabricate a biomimetic bone graft with both an interconnected porous structure analogous to that of trabecular bone and a bioactive nanostructured surface, via a combination of spongy replication and dip-coating technologies, and to investigate its osteoinductive potential in vitro and in vivo.

\section{Materials And Methods}

Fabrication Of BCP Scaffolds With

\section{Trabecular Framework}

Biphasic CaP (BCP) powders consisting of about $80 \%$ tricalcium phosphate (TCP) and 20\% HA were supplied by the Engineering Research Center in Biomaterials of Sichuan University, China. To prepare open porous bodies, an improved sponge replication method was adopted, following a procedure similar to that described previously. ${ }^{23}$ In brief, cylindrical polyurethane (PU) foams with high porosity ( 40 pores per inch) were impregnated into a series of BCP slurries with decreased viscosities, prepared by thoroughly dispersing gradually reduced amounts of BCP powders in a liquid containing polyvinyl alcohol (as a binder) and 25\% ethyl alcohol (as a dispersant). After several repetitions of coating/centrifuging/drying, a uniform slurry coating layer was formed on the spongy struts. Then, the green bodies were cut into discs $(\Phi 14 \times 3.5 \mathrm{~mm})$, which were sintered at $1100^{\circ} \mathrm{C}$ for $2 \mathrm{hrs}$ to fabricate porous BCP scaffolds (ie, the BCP substrate).

\section{Preparation Of BCP Scaffolds With Nanostructured Surface}

An nHA surface layer was coated onto the porous $\mathrm{BCP}$ discs. In brief, nHA particles were synthesized by combining wet chemical synthesis and hydrothermal treatment. ${ }^{24}$ A uniform nHA suspension was obtained by dispersing nHA particles in ultrapure water $\left(\mathrm{upH}_{2} \mathrm{O}\right)$ at a concentration of $20 \mathrm{mg} / \mathrm{mL}$ and treating with ultrasonic vibrations for $2 \mathrm{hrs}$. Pre-made porous BCP discs were soaked in the nHA slurry, kept under vacuum at $10^{-3} \mathrm{~Pa}$ for $0.5 \mathrm{hrs}$, washed with $\mathrm{upH}_{2} \mathrm{O}$, and then dried at $60^{\circ} \mathrm{C}$. The above process was repeated three times to ensure that the surface of the porous ceramic bodies was fully covered by nHA particles. Finally, heating at $650^{\circ} \mathrm{C}$ for $4 \mathrm{hrs}$ was used to fabricate BCP scaffolds with nanostructured surfaces (ie, nHA-coated BCP). Prior to in vitro and in vivo studies, the ceramic discs were sterilized by dry heat at $250^{\circ} \mathrm{C}$ for 2 hrs.

\section{Scaffold Characterization}

The surface morphology and micro-nano structure of nHA-coated and uncoated discs (BCP substrate and nHA-coated BCP) were observed by stereo microscopy (Leica, M205FA, Germany) and scanning electron microscopy (SEM, JSE-5900LV, Japan). To quantitatively measure scaffold structure, 10 randomly selected areas were 
selected from each optical or SEM image $(n=3)$ and analyzed using the Image J 1.44p software. Energy dispersive spectrometry (EDS) was performed to characterize the chemical composition of the scaffolds.

To investigate changes in the micro-nano surface topography of the porous ceramic scaffolds after the coating process and to eliminate interference from the 3D geometry, BCP ceramic discs with the same grain sizes but a smooth surface were obtained by uniaxially compacting the powder slurry and calcining it into tablets with surface structure that resembled that of the BCP substrates. Subsequently, nano-sized HA particles were deposited onto these tablets, following the process described above, to mimic the surface structure of porous nHA-coated BCP scaffolds. Finally, their surface area and roughness were measured by atomic force microscopy (AFM, Asylum Research, MFP-3D, Oxford Instruments, UK) in the trapping mode. The average surface roughness of each sample was quantified based on six randomly selected fields from three images.

\section{Cell Seeding And Cell Morphology}

Murine BMSCs were cultured and seeded as previously described. ${ }^{23}$ In brief, BMSCs were cultured in $\alpha$-minimum essential medium ( $\alpha$-MEM, Gibco, USA) containing $10 \%$ $\mathrm{v} / \mathrm{v}$ fetal bovine serum (Gibco, USA), $100 \mathrm{U} / \mathrm{mL}$ penicillin, and $100 \mu \mathrm{g} / \mathrm{mL}$ streptomycin (Gibco, USA). After $90 \%$ confluence was reached, BMSCs were detached with $0.25 \%$ trypsin solution, evenly dispersed in culture medium, and seeded onto porous ceramic discs $(5 \times 10$ cells/disc). Culture was performed in a humidified incubator at $5 \% \mathrm{CO}_{2}$ and $37^{\circ} \mathrm{C}$. At day 3, the samples were harvested, fixed in $2.5 \%$ glutaraldehyde at $4^{\circ} \mathrm{C}$, and then subjected to gradient dehydration using ethanol with volume fractions of $30 \%, 50 \%, 70 \%, 80 \%, 90 \%$, and $100 \%$ (twice). After sputter coating with gold, the samples were examined by SEM.

\section{Real-Time Quantitative Reverse Transcription PCR}

BMSCs were seeded onto porous ceramic discs $\left(1 \times 10^{5}\right.$ cells/ disc). Cells cultured on acid-cleaned glass coverslips were used as a control. Real-time quantitative reverse transcription PCR (qRT-PCR) analysis was used to assess the expression of specific osteogenic genes and cell signaling-related genes associated with the BMP/Smad signaling pathway, including bone morphogenetic protein-2 (BMP-2), runt-related transcription factor (Runx-2/Cbfa-1), osterix (OSX), alkaline phosphatase (ALP), bone sialoprotein (BSP), osteopontin $(\mathrm{OPN}), \mathrm{BMP}$ receptor type IA (BMPR1A), and mothers against decapentaplegic homolog 1 (Smad1) Smad4, and Smad5. Primers are listed in Table 1. In brief, at 1, 4, and 7 days, total RNA was extracted using an RNeasy Mini Kit RNA (Qiagen, Germany) from BMSCs seeded on BCP and nHA-coated BCP scaffolds $(n=3)$ and then reversed into cDNA using an iScript ${ }^{\mathrm{TM}}$ cDNA Synthesis kit (Bio-Rad, USA). Gene expression was detected using a CFX96 realtime thermal cycler system (Bio-Rad, USA) with SsoFast ${ }^{\mathrm{TM}}$ EvaGreen ${ }^{\circledR}$ Supermix (Bio-Rad, USA). Relative expression of each target gene was calculated by the $\Delta \Delta \mathrm{Ct}$-value method, using GAPDH as an internal reference to normalize the test results.

\section{ALP Activity And OCN Secretion}

To further evaluate material-stimulated osteoblastic differentiation, both osteogenic marker proteins, ie, ALP and

Table I Primer Sequences Used For Real-Time Quantitative Reverse Transcriptase Polymerase Chain Reaction (qRT-PCR)

\begin{tabular}{|c|c|c|}
\hline Gene & $5^{\prime}$ to $3^{\prime}$ & Primers \\
\hline BMP-2 & $\begin{array}{l}\text { Sense } \\
\text { Anti-sense }\end{array}$ & $\begin{array}{l}\text { GATCTGTACCGCAGGCACTCA } \\
\text { AAGCTTCCTGTATCTGTTCCCG }\end{array}$ \\
\hline Runx-2 & $\begin{array}{l}\text { Sense } \\
\text { Anti-sense }\end{array}$ & $\begin{array}{l}\text { AGCCTCTTCAGCGCAGTGAC } \\
\text { CTGGTGCTCGGATCCCAAA }\end{array}$ \\
\hline os $x$ & $\begin{array}{l}\text { Sense } \\
\text { Anti-sense }\end{array}$ & $\begin{array}{l}\text { ATGGCGTCCTCTCTGCTTG } \\
\text { TGAAAGGTCAGCGTATGGCTT }\end{array}$ \\
\hline ALP & $\begin{array}{l}\text { Sense } \\
\text { Anti-sense }\end{array}$ & $\begin{array}{l}\text { ATCTTTGGTCTGGCTCCCATG } \\
\text { TTTCCCGTTCACCGTCCAC }\end{array}$ \\
\hline BSP & $\begin{array}{l}\text { Sense } \\
\text { Anti-sense }\end{array}$ & $\begin{array}{l}\text { GTTTCAGCAGACAACCCCACC } \\
\text { CTCCCCGTTCTCGTTGTCATA }\end{array}$ \\
\hline OPN & $\begin{array}{l}\text { Sense } \\
\text { Anti-sense }\end{array}$ & $\begin{array}{l}\text { CCCTCGATGTCATCCCTGTT } \\
\text { CCCTTTCCGTTGTTGTCCTG }\end{array}$ \\
\hline BMPRI & $\begin{array}{l}\text { Sense } \\
\text { Anti-sense }\end{array}$ & $\begin{array}{l}\text { CCTGTTGTTATAGGTCCGTTCTT } \\
\text { AGCTGGAGAAGATGATCATAGCA }\end{array}$ \\
\hline SmadI & $\begin{array}{l}\text { Sense } \\
\text { Anti-sense }\end{array}$ & $\begin{array}{l}\text { GGATGAGCTTCGTGAAGGGTTGG } \\
\text { GCAAGAGACGGAAGCCACAGG }\end{array}$ \\
\hline Smad4 & $\begin{array}{l}\text { Sense } \\
\text { Anti-sense }\end{array}$ & $\begin{array}{l}\text { GTGACTGTGGATGGCTATGTGG } \\
\text { GCAACCTCGCTCTCTCAATCG }\end{array}$ \\
\hline Smad5 & $\begin{array}{l}\text { Sense } \\
\text { Anti-sense }\end{array}$ & $\begin{array}{l}\text { ATCCCACCACTGTCTGTAAG } \\
\text { TTTATCCAGCCACTGAAGAGG }\end{array}$ \\
\hline GAPDH & $\begin{array}{l}\text { Sense } \\
\text { Anti-sense }\end{array}$ & $\begin{array}{l}\text { TGGTGAAGGTCGGTGTGAAC } \\
\text { CCATGTAGTTGAGGTCAATGAAGG }\end{array}$ \\
\hline
\end{tabular}


osteocalcin $(\mathrm{OCN})$, were quantitatively measured. After coculturing BMSCs with BCP and nHA-coated BCP scaffolds for 7 and 14 days, cells were harvested, lysed using RIPA Lysis Buffer (Boster, Wuhan, China), and centrifuged at $8000 \mathrm{rpm}$ for $10 \mathrm{mins}$ to collect the supernatant. Then, according to the manufacturer's specification, ALP and OCN contents were determined using a commercialized ALP assay kit (SensoLyte ${ }^{\circledR}$ pNPP ALP assay kit, CA, USA) and murine osteocalcin ELISA kit (Cloud-clone Corp, USA), respectively. The relative amount of ALP and OCN per unit protein was normalized to the total protein content, which was measured with a Pierce ${ }^{\mathrm{TM}}$ BCA Protein Assay Kit (Thermo Scientific, USA).

\section{In Vivo Animal Studies}

The animal experimental procedure was approved by the Animal Care and Use Committee of Sichuan University, China, following the Guide for the Care and Use of Laboratory Animals published by the Chinese National Academy of Sciences. Three healthy male New Zealand white rabbits $(2-2.5 \mathrm{~kg})$ purchased from Chengdu Dashuo Experimental Animal Co., Ltd. were subjected to intramuscular implantation surgery to evaluate the osteoinductivity of the two porous scaffolds. Briefly, each rabbit was anesthetized by pentobarbital sodium with a dose of $40 \mathrm{mg}$ per kg body weight. Then, three longitudinal blunt incisions ( $2 \mathrm{~cm}$ in length) spaced about $3 \mathrm{~cm}$ apart were made within the dorsal muscle on each side of the bilateral spine and filled with porous scaffolds (one per incision). Finally, incisions were sutured layer by layer. All rabbits were able to function normally post-surgery. Three months after implantation, samples $(n=9)$ were harvested and fixed in $4 \%$ phosphate-buffered paraformaldehyde solution for 5 days before further analysis.

\section{Histological And Immunofluorescent Analyses}

The fixed samples were decalcified with $10 \%$ EDTA $(\mathrm{pH}$ 7.4), dehydrated in ascending concentrations of ethanol from $70 \%$ to $100 \%$, and then embedded in paraffin. Each specimen was transversely cut into thin sections $(5 \mu \mathrm{m}$ in thickness) parallel to the direction of the disc plane using a microtome (Leica, Germany). Finally, some tissue sections were stained with hematoxylin and eosin (HE) and examined by Panoramic 250/MIDI (3D HISTECH, Hungary) and CaseViewer 2.0 software for histological observation. The others were subjected to co-staining with DAPI, rabbit-anti-mouse osteocalcin primary antibody, and goatanti-rabbit fluorescent secondary antibody (Servicebio, China), and visualized under a fluorescence microscope (Leica, Germany) for immunofluorescence analysis.

\section{Statistical Analysis}

All quantitative measurements were calculated from at least three test values and presented as mean \pm standard deviation. Statistical analysis was performed using oneway analysis of variance. A p-value of less than 0.05 was considered to indicate a statistically significant difference.

\section{Results}

\section{Characterization Of Biomimetic Scaffolds}

The scheme used to fabricate the nHA-coated BCP scaffold is illustrated in Figure 1A. Stereo microscopy photos and SEM images (Figure 1B and C) showed a highly interconnected porous structure for both ceramics $(\Phi 10.7 \times 3.0 \mathrm{~mm})$ that replicated the texture of a PU sponge. The images also showed that the BCP and nHA-coated BCP scaffolds exhibited similar trabecular bone-like structures with open macropores $(\sim 700 \mu \mathrm{m})$; many micropores $(<10 \mu \mathrm{m})$ were also present on the scaffold structures $(\sim 180 \mu \mathrm{m})$. However, the surface architecture of the nHA-coated scaffolds was significantly different from that of the BCP substrates, in that the former exhibited a nanoparticle covering and an increased number of nanopores $(<100 \mathrm{~nm})$, whereas the latter was composed of micron-scale grains. Cross-section images indicated that an nHA particle surface layer with a thickness of approximate $1 \mu \mathrm{m}$ was uniformly deposited onto the BCP substrate. The scaffolds were weighed before and after coating to quantify the nHA layer; the nHA coating process increased the total mass by $3.63 \pm 0.6 \%$. EDS analysis (Supplementary Figure 1) showed that both the coating layer and substrate were mainly composed of $\mathrm{Ca}$, $\mathrm{P}$, and $\mathrm{O}$, although the ratios of calcium to phosphorus were significantly different in the two cases, with values of about 1.665 and 1.529 , respectively. These findings were consistent with the X-ray diffraction results of our previous study, ${ }^{23}$ suggesting that the substrate comprised both an HA phase $(\mathrm{Ca} / \mathrm{P}=1.67)$ and a TCP phase $(\mathrm{Ca} / \mathrm{P}=1.5)$, whereas the coating layer consisted of pure HA phase.

Representative AFM images revealing the surface micro-nano structure are shown in Figure 2. As can be seen from the topographic $3 \mathrm{D}$ view, the $\mathrm{BCP}$ specimen had a relatively smooth surface with a flaky texture 


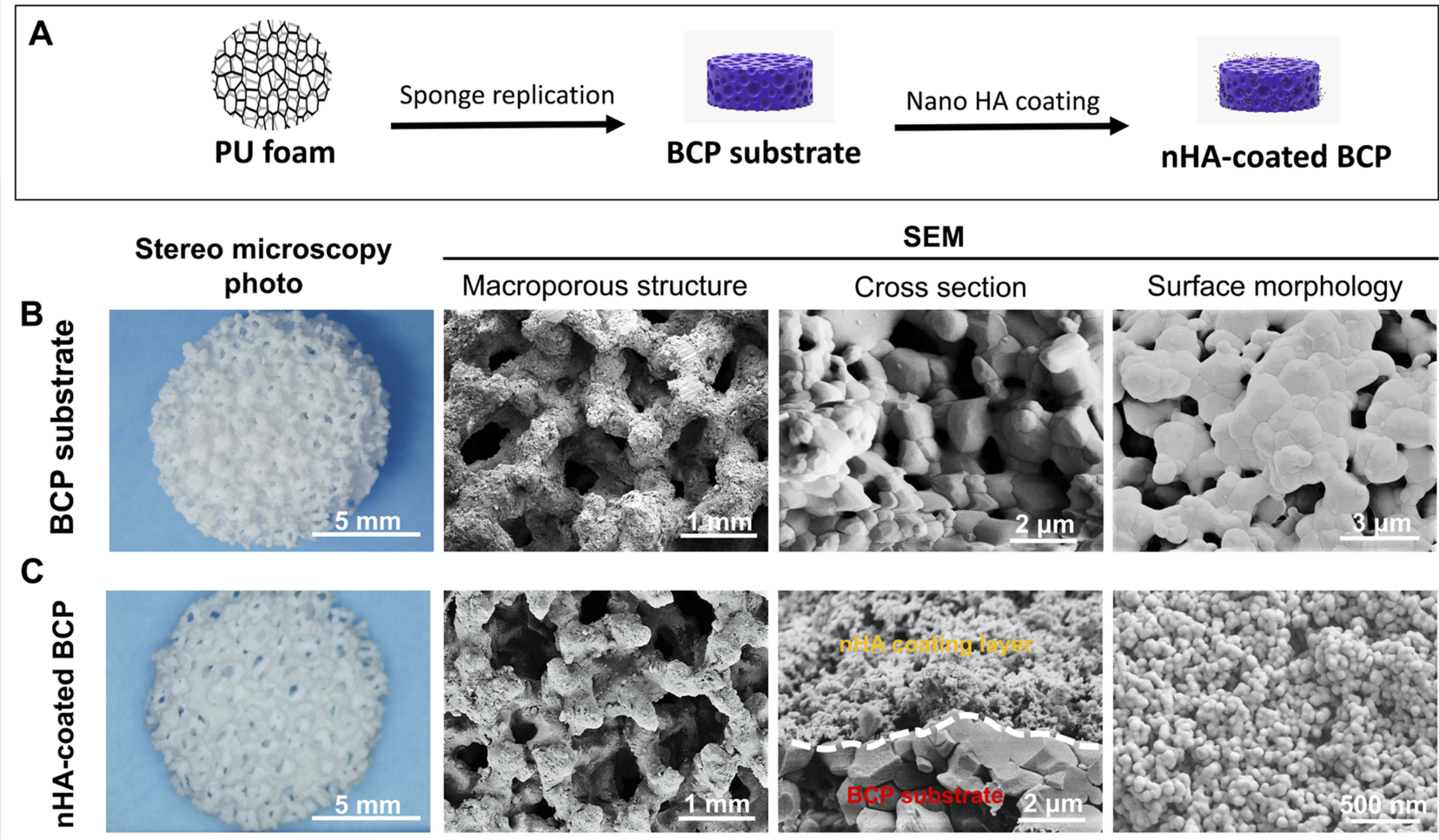

Figure I Scheme illustration for the fabrication process of BCP substrate and nHA-coated BCP scaffold (A). Stereo microscopy photos, SEM images of macroporous structure, cross-section, and surface morphology for $\mathrm{BCP}$ substrate $(\mathbf{B})$ and $\mathrm{nHA}$-coated $\mathrm{BCP}(\mathbf{C})$.

(Figure 2A), whereas the nHA particles resulted in abundant nano-sized peaks and valleys on the nHA-coated specimen (Figure 2C). The topographic top view of the surface given by the AFM images demonstrated that the surface of the nHA-coated specimen (Figure 2D) had a dramatically smaller grain size than that of the BCP scaffold (Figure 2B). The surface grain size and surface roughness of both ceramics are summarized in Table 2. Consistent with the SEM observations (Figure 1), the mean surface grain sizes of the BCP and nHA-coated samples were $961.1 \pm 420.1 \mathrm{~nm}$ and $55.9 \pm 11.7 \mathrm{~nm}$, respectively. AFM analysis also gave a surface roughness of $67 \pm 5 \mathrm{~nm}$ for the BCP scaffold, and a slightly higher value of $72 \pm 4 \mathrm{~nm}$ for the nHA-coated sample.

\section{Cell Adhesion And Morphology}

As cells can be significantly affected by the surface topography of bioceramics, in particular, nano-scale surface structure, the adhesion and spreading of BMSCs on the two trabecular-like scaffolds (ie, BCP substrates and nHA-coated BCP scaffolds) were observed using SEM after 3 days of culture. As shown in Figure 3, BMSCs presented typical fibroblast-like phenotypes and attached firmly to both scaffolds. High-magnification images (Figure 3C and F) showed that BMSCs seeded on nHA-coated scaffolds, compared with those on BCP substrates, exhibited more slender extending processes (filopodia), which tightly grasped nano-scale grains.

\section{Osteogenic Differentiation Of BMSCs Expression Of Osteogenic Genes}

qRT-PCR was used to measure the expression levels of six typical osteogenic genes (BMP-2, Runx2, OSX, ALP, BSP, and OPN) in BMSCs co-cultured with BCP and nHA-coated scaffolds for 1, 4, and 7 days (Figure 4). Expression levels of all osteogenic genes in the BCP group dramatically decreased over time, whereas gene expression in the nHA-coated BCP group remained at a relatively high level during the whole culture period. Moreover, the BMP-2, OSX, and OPN genes had the highest expression levels in the nHA-coated BCP group at all time points. Compared with the BCP group and blank controls, the nHA-coated BCP scaffolds showed significantly upregulated expression of the Runx2 gene at day 4, and increased expression of ALP and BSP genes at days 4 and 7 . Overall, these results demonstrate that the introduction of an nHA coating onto trabecular 
A

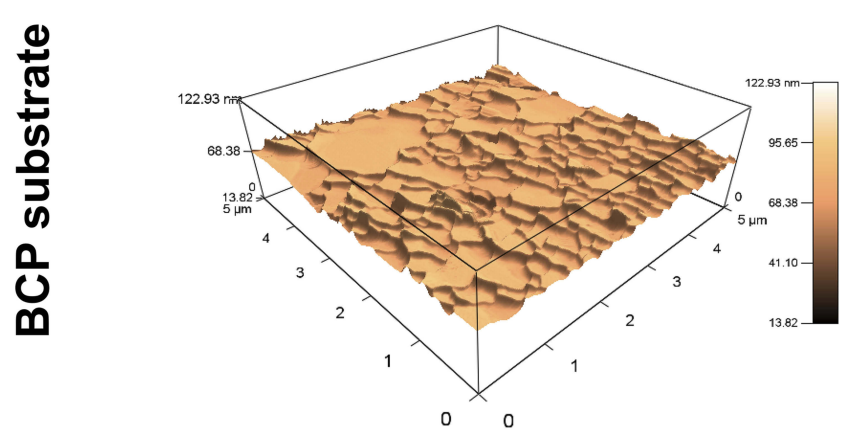

B

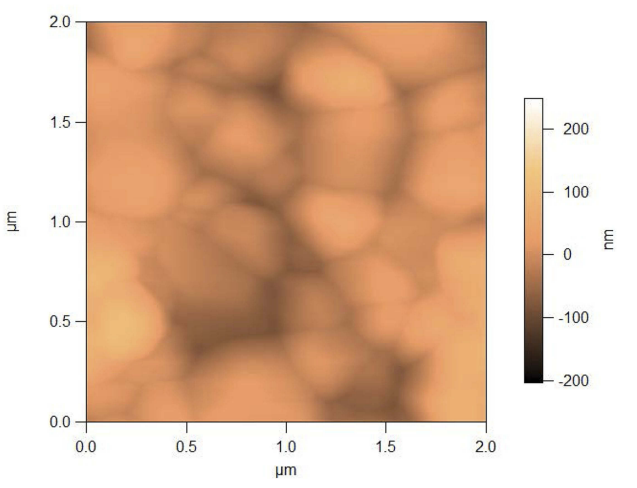

C

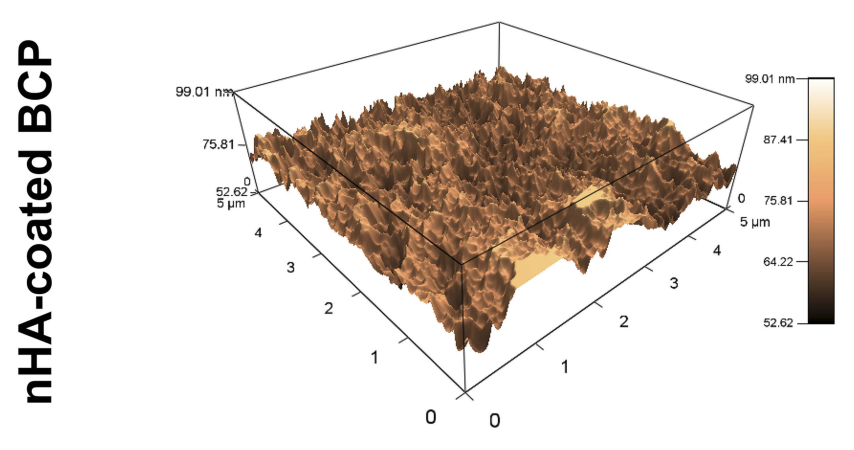

D

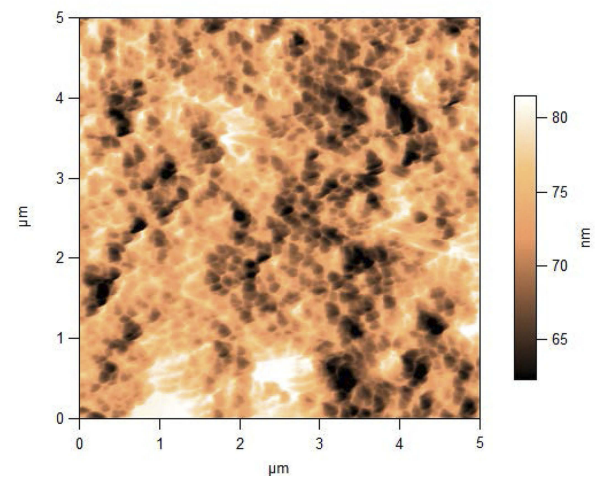

Figure 2 AFM topographic images for 3D view (A) and top view (B) of BCP substrate; 3D view (C) and top view (D) of $n H A-c o a t e d ~ B C P$ scaffold.

Table 2 Scaffold Characterization Of BCP Substrate And nHACoated Scaffold

\begin{tabular}{|l|l|l|}
\hline & $\begin{array}{l}\text { BCP } \\
\text { Substrate }\end{array}$ & $\begin{array}{l}\text { nHA-Coated } \\
\text { Scaffold }\end{array}$ \\
\hline $\begin{array}{l}\text { Mean grain size (nm) } \\
\text { Ra (nm) }\end{array}$ & $961.1 \pm 420.1$ & $55.9 \pm 11.7$ \\
$67 \pm 5$ & $72 \pm 4$ \\
\hline
\end{tabular}

bone-like scaffolds can enhance the expression of several important genes related to osteoblastic differentiation.

\section{ALP Activity And OCN Production}

Quantitative analyses were used to determine intracellular ALP activity and OCN production in BMSCs cultured on the two trabecular-like scaffolds. As shown in Figure 5, ALP activity was significantly higher in the nHA-coated BCP group than in the BCP group at day 7 $(p<0.01)$. The control group always had the lowest ALP activity at day 7 and $14(\mathrm{p}<0.05$, Figure 5A). There was a slight decrease in ALP activity and an increase in OCN production by BMSCs with increasing culture time, showing statistically significant differences among the different groups with ALP and OCN values from high to low: nHA-coated $\mathrm{BCP}>\mathrm{BCP}>$ Control $(\mathrm{p}<0.05$, Figure 5B).

\section{Expression Of Genes Related To BMP/Smad Signaling Pathway}

Furthermore, to explore the possible mechanism of osteogenesis stimulated by nHA coating layers, mRNA expression levels of several genes related to BMP/Smad signaling (BMPRI, Smad1, Smad4, and Smad5) were investigated using qRT-PCR. As shown in Figure 6, compared with the BCP group, the nHAcoated BCP group showed significantly upregulated expression of the BMPRI gene at day $1 \quad(\mathrm{p}<0.01)$. The Smad genes (Smad1, Smad4, and Smad5) reached their highest expression levels in BMSCs cultured on nHA-coated BCP scaffolds at day 1 and $4(\mathrm{p}<0.05)$. 

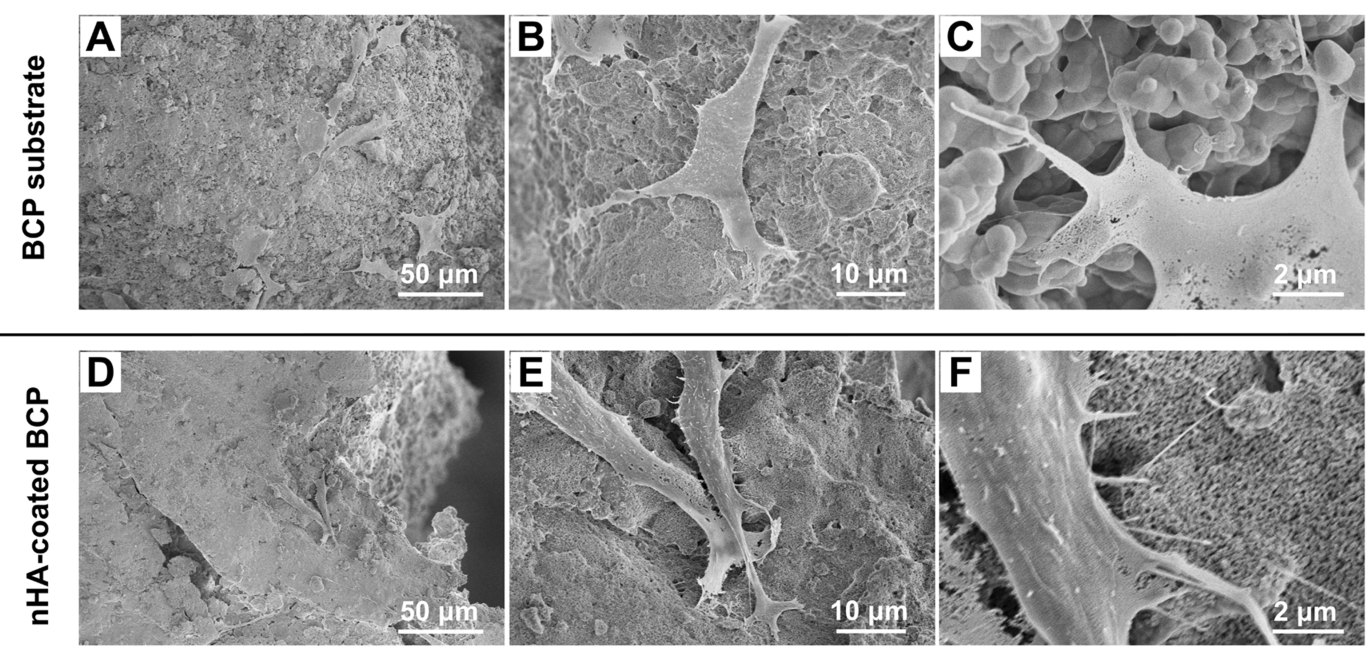

Figure 3 SEM micrographs of BMSC attachment onto the surface of BCP substrates (A-C) and nHA-coated BCP scaffolds (D-F) at day 3.

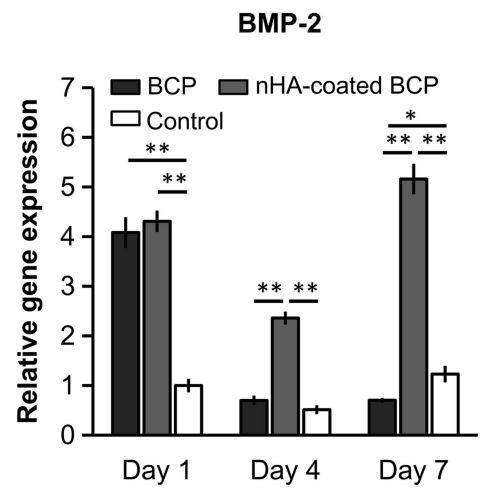

ALP

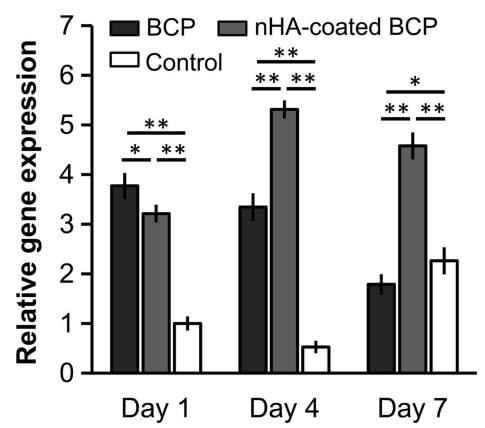

Runx2

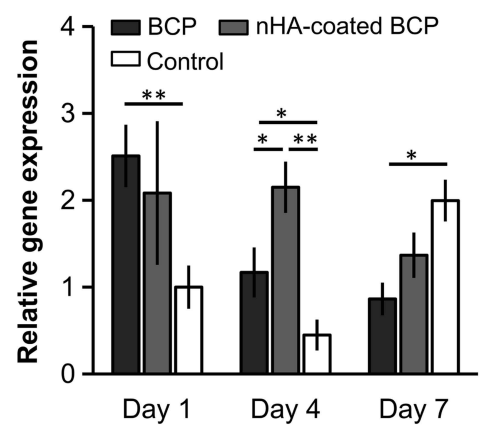

BSP

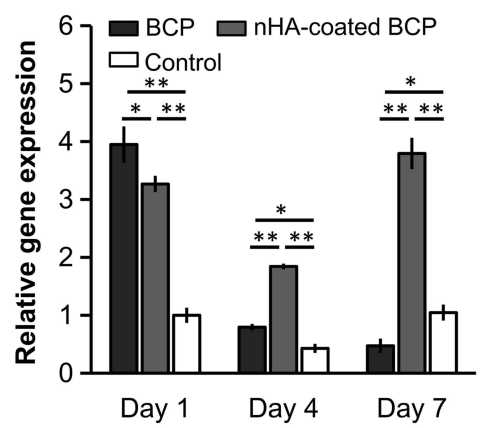

osx
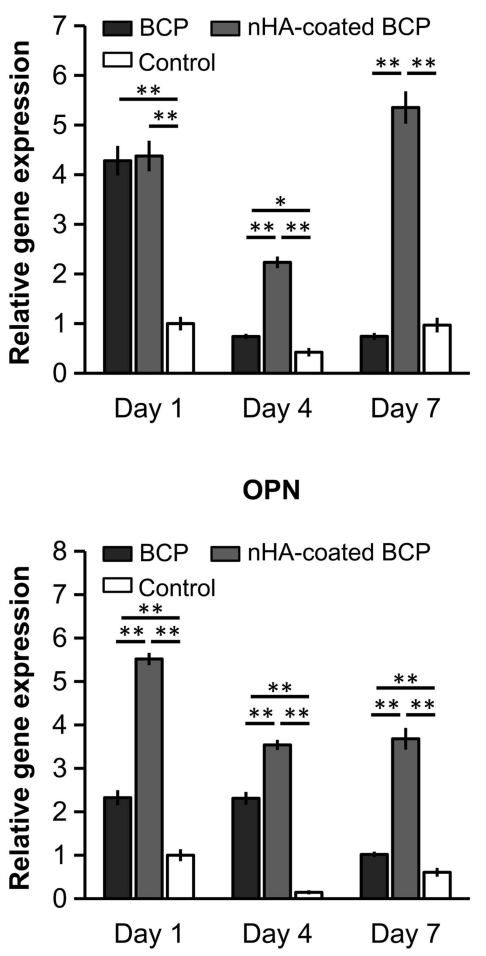

Figure 4 The expression of specific osteogenic genes (BMP-2, Runx2, OSX, ALP, BSP and OPN) in BMSCs cultured in BCP, nHA-coated BCP and control group for I, 4 and 7 days. * refers to $p<0.05$, $* *$ refers to $p<0.01$.

\section{In Vivo Ectopic Bone Formation}

To further evaluate the osteoinductive capacity of the two trabecular-like scaffolds, a rabbit intramuscular implantation model was established by implanting two scaffolds (BCP and nHA-coated $\mathrm{BCP}$ ) into the rabbit's back muscle for 90 days (Figure 7A).

\section{Micro-CT Analysis}

Micro-CT ( $\mu-\mathrm{CT})$ imaging was used to examine structural changes in the BCP and nHA-coated BCP scaffolds before and after implantation (Figure 7B and C). Prior to implantation, both biomimetic scaffolds had architectural structures similar to that of trabecular bone, consistent with the microscopy 


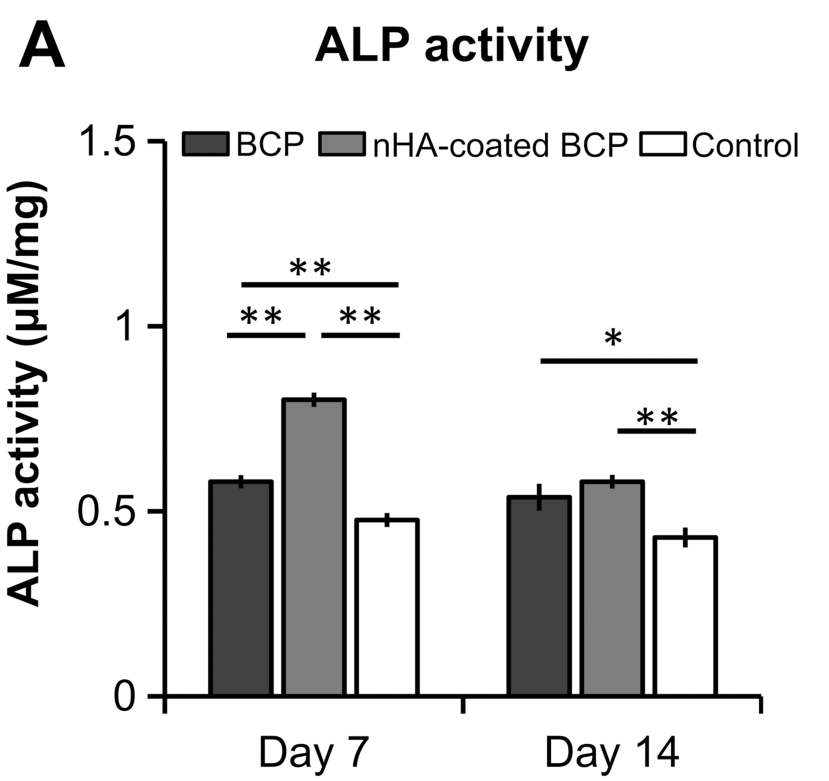

B OCN production

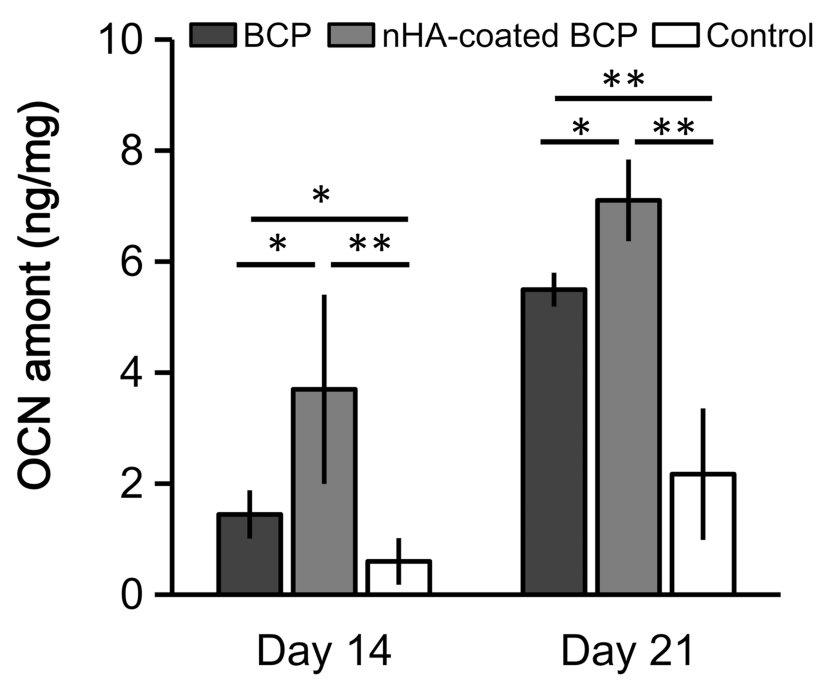

Figure 5 Intracellular ALP activity (A) and OCN production (B) for BMSCs cultured in $\mathrm{BCP}, \mathrm{nHA}$-coated $\mathrm{BCP}$ and control group. * refers to $\mathrm{p}<0.05$, ** refers to $\mathrm{p}<0.0 \mathrm{I}$.

observations (Figure 1B and C). After intramuscular implantation for 90 days, however, the BCP scaffold had mostly disintegrated and its original macroporous structure was largely destroyed, whereas the nHA-coated BCP scaffold essentially maintained its original geometric shape.

\section{Histological Analysis And Immunofluorescent Staining}

The HE staining results also showed that almost all of the BCP scaffolds were degraded after 90-day implantation, with a few sporadic fragments remaining (Figure 8A).
Muscle tissue filled the void resulting from degradation, accompanied by a mass of inflammatory cells in the surrounding area (indicated by a yellow arrow in the figure). However, the nHA-coated BCP samples maintained their original highly porous architecture (Figure $8 \mathrm{~B}$ ), with invasion of blood vessels and the ingrowth of cells, and had formed ectopic bone after 90 days of implantation, as evidenced by the bone lacuna and mature bone cells observed at the periphery of the scaffold struts (indicated by a black arrow in the figure). Immunofluorescence staining images (Figure 8C and D; green fluorescence represents OCN expression and blue indicates cell nuclei) results showed the presence of osteocalcin protein in the nHA-coated BCP group but not in the BCP group.

\section{Discussion}

$\mathrm{CaP}$ bioceramics have been extensively used as bone substitutes in orthopedic treatment. It is believed that proper material design can endow $\mathrm{CaP}$ bioceramics with excellent osteoinductivity that enhances self-renewal and self-repair in patients. ${ }^{25,26}$ However, the bioactivity of conventional $\mathrm{CaP}$ ceramics is generally lower than that of humanderived bone grafts (autografts and allografts). This may be because although $\mathrm{CaP}$ ceramics resemble the inorganic components of natural bone tissues, it is difficult for them to recapitulate the complex hierarchical structure of bones. Native cancellous bone is composed of collagen fibers and HA nanocrystals, and has a highly interconnected porous structure that contributes to its unique mechanical and biological properties. ${ }^{27}$ From a biomimetics perspective, it is thought that the biological performance of $\mathrm{CaP}$ ceramics could be markedly improved by fully simulating the hierarchical structure of cancellous bone and introducing biomimetic nano-sized HA particles. Therefore, in this study, porous BCP scaffolds were prepared via an improved sponge replication method to mimic the trabecular framework. A surface layer of nHA was uniformly deposited onto this BCP substrate to construct a bionic surface with nanocrystalline structure (ie, nHA-coated $\mathrm{BCP}$ ). Stereo microscopy and SEM images showed that the BCP substrates and nHA-coated BCP scaffolds had similar trabecular bone-like structures with high porosity and excellent interconnectivity, consistent with previous studies, indicating that both scaffolds had abundant macropores $(200-700 \mu \mathrm{m})$, minorpores $(20-50 \mu \mathrm{m})$, micropores $(0.1-2 \mu \mathrm{m})$, and nanopores $(30-100 \mathrm{~nm}){ }^{23}$ Micro-tomacropores are thought to benefit nutrient exchange and favor tissue ingrowth. ${ }^{3,8,9}$ However, it has also been 


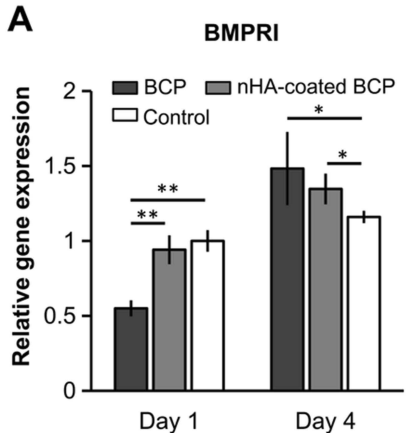

B

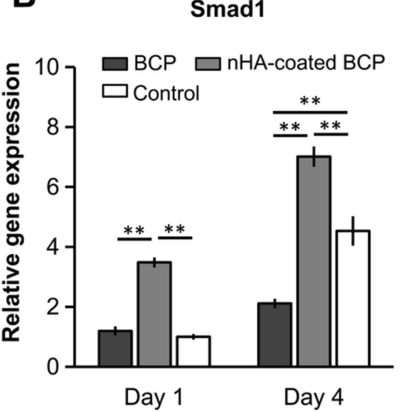

C

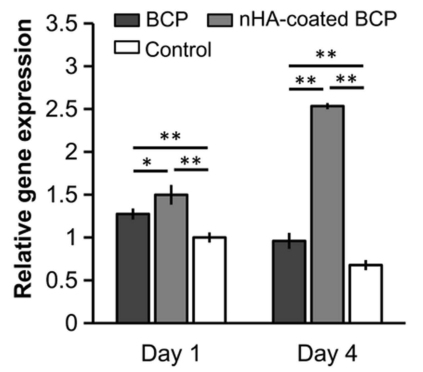

D

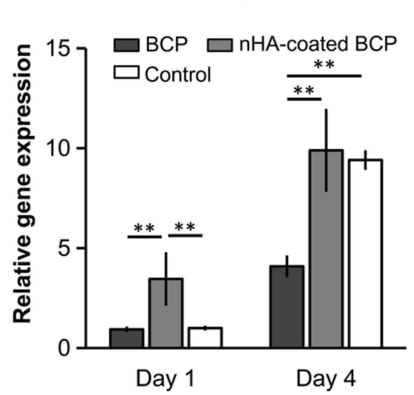

E
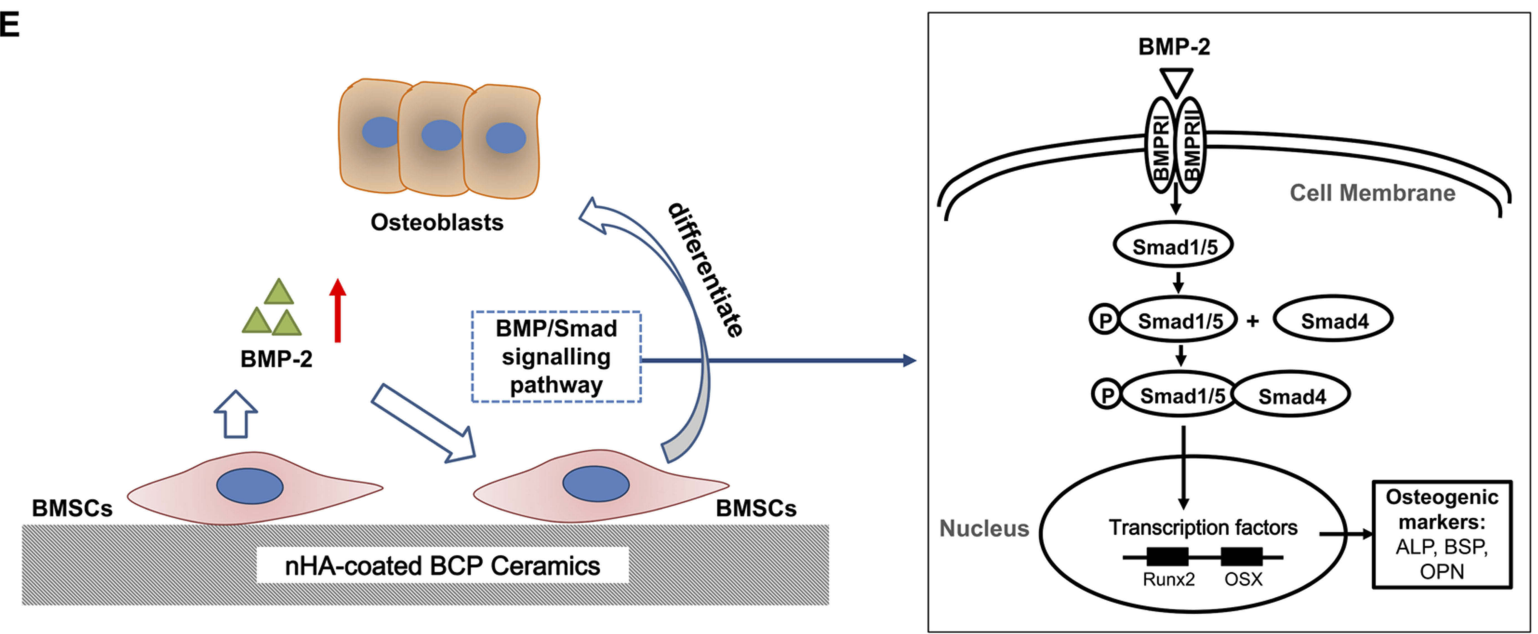

Figure 6 The expression of genes related to BMP/Smad signals - BMPRI (A), SmadI (B), Smad4 (C), and Smad5 (D). Schematic illustration of the possible involvement of BMP/Smad signaling pathway in pro-osteogenic effects of nanostructured surface (E). * refers to $p<0.05$, ** refers to $p<0.01$.

suggested that the nHA coating process could significantly increase numbers of micropores and nanopores, ${ }^{23}$ and indeed the two trabecular bone-like scaffolds had markedly different surface structures: the nHA-coated BCP scaffolds were covered uniformly by a layer of nanosized HA particles with mean grain sizes of $\sim 55 \mathrm{~nm}$, whereas the BCP substrates had a micron-scale surface architecture with mean grain sizes of $\sim 1 \mu \mathrm{m}$.

In recent years, nanostructured surfaces have received increasing attention. Extensive studies have demonstrated that use of an nHA coating layer confers strong adsorption capacity and provides abundant active sites for cell attachment owing to its large surface area and high surface energy. ${ }^{28-30}$ Thus, the roles of nanostructured surfaces on biomimetic bone grafts in material-induced osteogenesis were evaluated by comparing the osteoinductivity of $\mathrm{BCP}$ and nHA-coated BCP in vitro and in vivo. SEM images showed that nHA-coated BCP scaffolds, compared with BCP alone, better enabled BMSCs to stretch out filopodia to grasp nano-scale grains and to adhere more tightly to the scaffold surface, consistent with previous findings. ${ }^{31,32}$ It has been reported that when the grains of a $\mathrm{CaP}$ ceramic were decreased to nano-size, cell morphology was affected more by nanotopography than by chemical composition. ${ }^{33,34}$ Thus, the differential cellular adhesive patterns and morphology of BMSCs could be attributed to the distinct surface structures of the $\mathrm{BCP}$ and $\mathrm{nHA}$-coated BCP scaffolds. The nHA-coated group was uniformly covered by nano-sized particles (less than $100 \mathrm{~nm}$ in size), resulting in a high specific surface area and abundant active calcium and phosphate sites, which could be beneficial to cell adhesion and spreading. Moreover, nano-scale grains might be more suitable for the anchorage of cellular filopodia, which are also nano-sized. ${ }^{33}$

In nature, osteogenesis requires the cascade activation of a series of osteogenic-specific marker genes and proteins, including BMP-2, OSX, Runx2, ALP, and OCN. Runx2, OSX, and ALP are widely considered to be early markers 

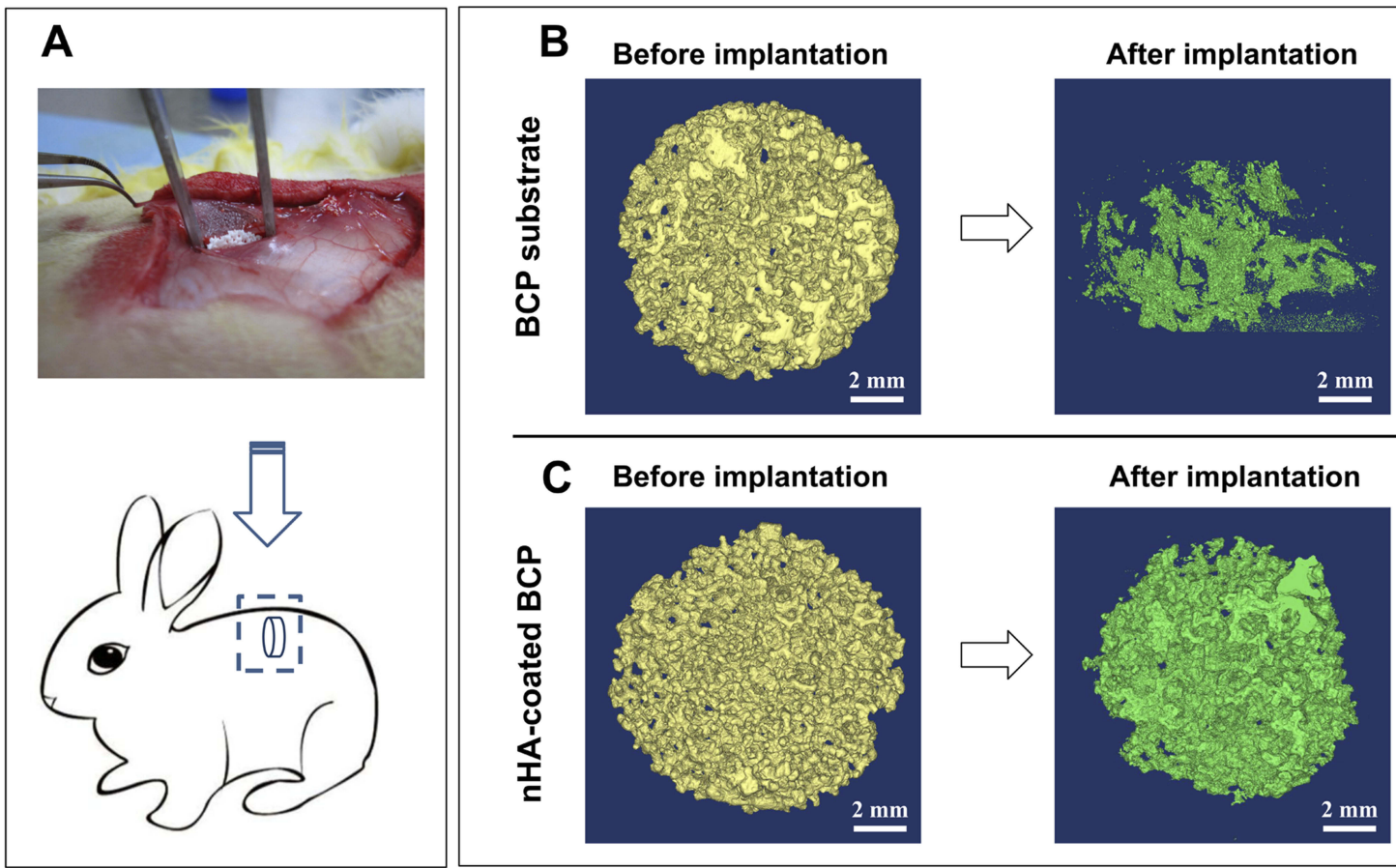

After implantation

Figure 7 A rabbit intramuscular implantation model for the evaluation of material's osteoinductivity $(\mathbf{A})$; $\boldsymbol{\mu}$-CT images for structural changes of $\mathrm{BCP}(\mathbf{B})$ and $\mathrm{nHA}$-coated BCP scaffolds $(\mathbf{C})$ before and after implantation.

\section{HE Staining}
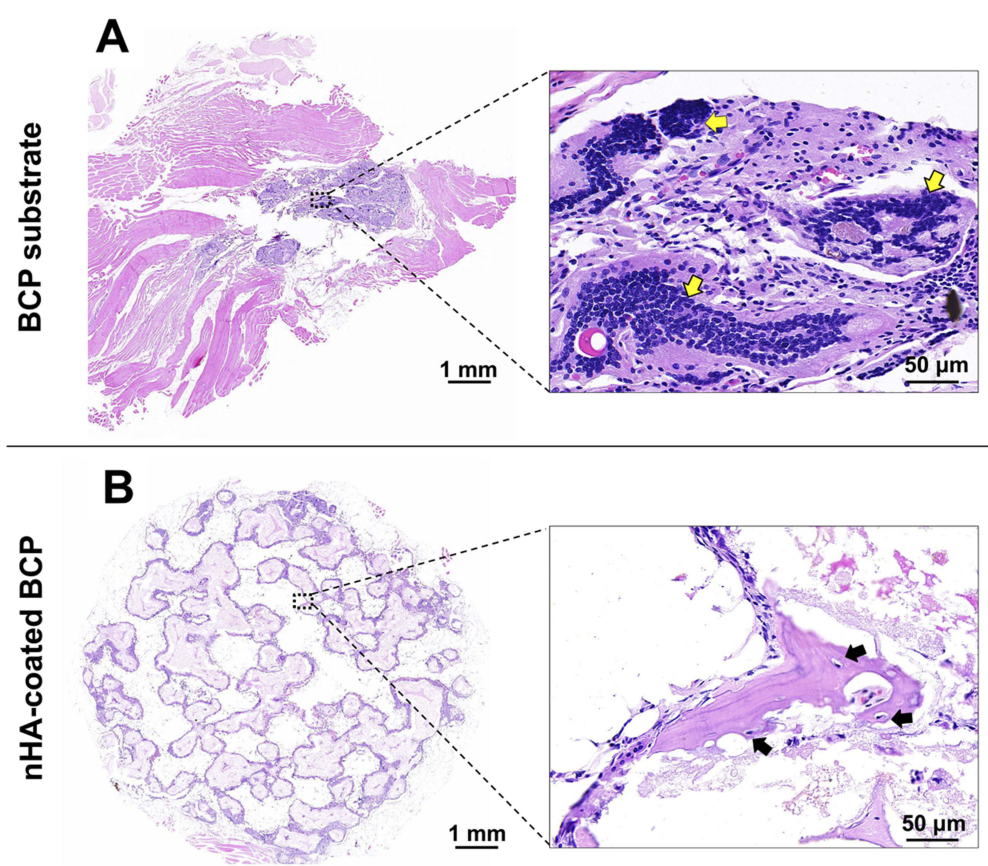

\section{Immunofluorescent staining}

\section{C}

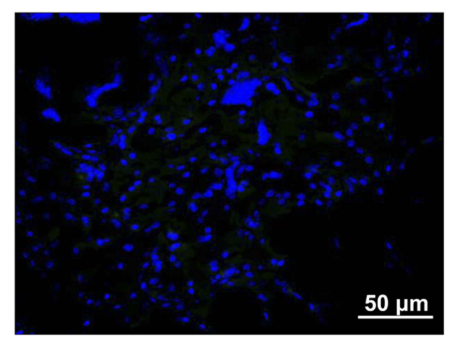

D

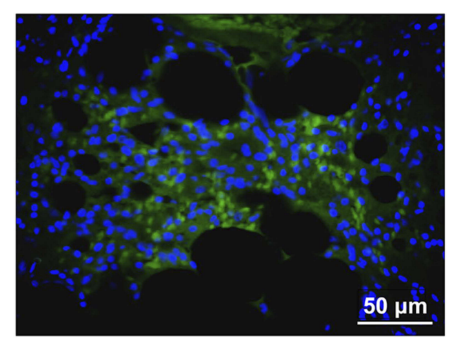

Figure 8 HE histological analysis of in vivo ectopic bone formation ability for BCP (A) and nHA-coated BCP (B) scaffolds after implanted in back muscles of rabbits for 90 days. Yellow arrows: inflammatory cells; black arrows: bone formation as evidenced by osteocytes settled in bone lacuna. Immunofluorescent staining of osteocalcin (OCN) for BCP $(\mathbf{C})$ and nHA-coated BCP (D) groups. Green and blue colors represented osteocalcin and DAPI-stained nuclei, respectively.

for pre-osteoblasts, whereas BSP, OPN, and OCN are late markers for mature osteoblasts. ${ }^{35,36}$ It is well known that cell differentiation is affected by interactions at the interface between the material surface and cells. ${ }^{37}$ Here, qRT-PCR 
analyses showed that the two trabecular bone-like scaffolds enhanced expression of osteogenic marker genes compared with blank controls. The nHA-coated BCP group with a nano-sized HA coating layer exhibited significantly higher expression of osteogenesis-associated genes than the $\mathrm{BCP}$ group with microtopography, in good agreement with previous research. ${ }^{29,38-40}$ Moreover, ALP and OCN are recognized as important specific proteins for osteogenic differentiation of BMSCs at the early and late stage, respectively. ${ }^{36,41}$ In this study, biochemical analyses and ELISA assays showed higher ALP activity in the early stages (day 7), whereas OCN production increased with culture time. Compared with the BCP group, the nHA-coated group dramatically promoted ALP activity and OCN production at each time point. This suggests that the nHA-coated scaffolds with nanostructure surface were more beneficial for direct BMSC differentiation into an osteoblast lineage, compared with BCP substrates with micro-sized grains. These findings are consistent with those of previous studies, which showed that nano-sized ceramics exhibited superior biological ability and induced osteogenic differentiation of stem cells. ${ }^{42,43}$

The underlying mechanism of the pro-osteogenic effects of the nanostructured surface was further investigated. The qRT-PCR results showed that BMP-2 gene expression in BMSCs cultured on nHA-coated BCP scaffolds, compared with those cultured on BCP alone, increased by $235.5 \%$ at day 4 and by $634.4 \%$ at day 7 . BMP-2 is the best-studied pro-osteogenic growth factor, and the BMP/Smad signaling pathway is known to have a significant role in regulating cellular events such as cell morphogenesis and differentiation. ${ }^{44}$ We also found that the nHA-coated BCP scaffolds could upregulate expression of BMP/Smad signaling-related genes (ie, BMPR1, Smad1, Smad4, and Smad5) in BMSCs. As shown in Figure 6E, BMP-2 promotes the phosphorylation of Smad1/5 proteins, which translocate into the nucleus with the help of Smad4 and trigger further transcription factor cascades to activate the expression of osteogenesisspecific genes (eg, ALP, BSP, OPN, and OCN), finally inducing the osteoblastic differentiation of BMSCs. ${ }^{45,46}$ Therefore, our results indicate that the secretion of BMP-2 proteins stimulated by the nanostructured surface may drive BMSCs into an osteoblastic lineage through the $\mathrm{BMP} / \mathrm{Smad}$ signaling pathway.

The results of the intramuscular implantation experiment indicated that the nanostructured surface also plays a vital part in maintaining the integration of implants and inducing ectopic bone formation. The $\mu$-CT scanning and histological examination results showed severe degradation in the BCP group 90 days after implantation, resulting in the loss of primary architecture with only a few sporadic ceramic fragments remaining. By contrast, the nHA-coated BCP scaffolds tended to maintain their original porous structure. This discrepancy may be due to the high porosity of the scaffold, which had numerous interconnected pores and channels within the materials. Blood vessels and cells can completely invade such porous structures as blood flows through penetrating channels, which enables material biodegradation. It has also been shown that sponge replication techniques often cause defects (eg, pores and cracks) on scaffold walls, as well as formation of internal voids in scaffold struts, owing to the removal of the PU foam, ${ }^{47}$ which may lead to fast degradation and even the collapse of the whole structure. For instance, Renghini et al showed that porous scaffolds made by a sponge replication method were already affected by biodegradation after 1 week of immersion in Tris- $\mathrm{HCl}$ solution, and that the mean thickness of scaffold walls decreased by one-third after 4 weeks of immersion. ${ }^{48}$ Moreover, in this study, the BCP scaffolds had a high proportion $(80 \%)$ of $\beta$-TCP phase, which might represent another reason for their fast degradation, as previous results have suggested that $\mathrm{BCP}$ is a thermodynamically reactive compound, especially when $\beta$-TCP accounts for a high proportion. ${ }^{49,50} \mathrm{HE}$ staining results also indicated that the fast degradation of BCP scaffolds led to the recruitment of inflammatory cells with no osteogenesis, whereas the nHA-coated BCP scaffolds induced bone formation in non-osseous sites, as evidenced by the presence of mature bone cells settled in bone lacuna. This might be because maintenance of the three-dimensional porous structure provides the necessary environment for osteogenesis. Fast implant degradation can lead to the release of wear debris, which causes chronic inflammation and triggers the secretion of pro-inflammatory factors, chemokines, and pro-osteoclastic factors (eg, RANKL), resulting in the migration, differentiation, and activation of bone-resorbing cells (osteoclasts) that further accelerate implant biodegradation. ${ }^{51}$ Interactions between inflammatory cells and implant-derived wear debris are considered to be a key factor in periprosthetic bone resorption (osteolysis) and even implant aseptic loosening. ${ }^{52}$ Moderate inflammation promotes osteogenesis, whereas an excessive inflammatory response is detrimental to osteogenesis. In addition, rapid leaching of the $\mathrm{HA}$ layer could lead to weak 


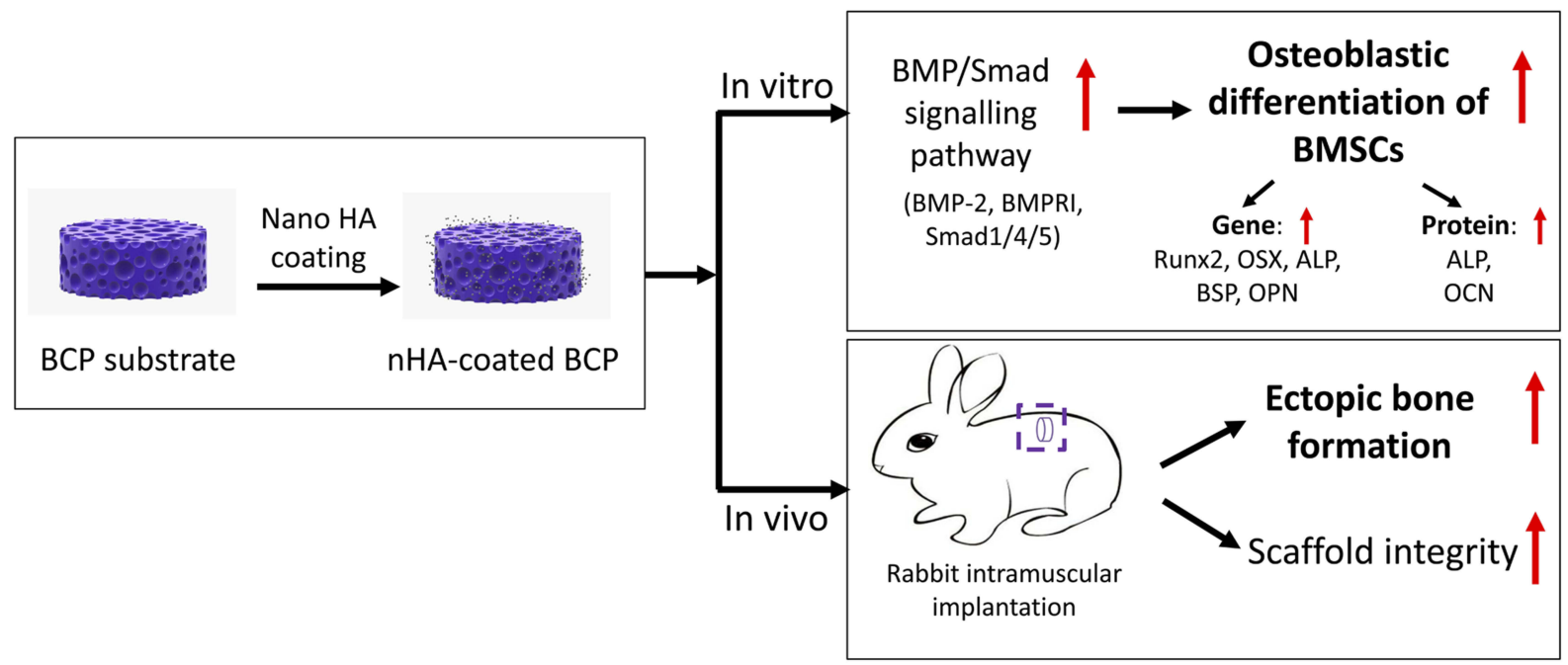

Figure 9 Scheme illustration demonstrated that $\mathrm{nHA}$-coated BCP scaffolds could stimulate osteogenic differentiation via BMP/Smad signaling pathway in vitro, and induce ectopic bone formation in vivo.

bioactivity; previous experiments showed that poor cell adhesion and spreading could be attributed to rapid dissolution and reprecipitation of ceramics, ${ }^{53}$ whereas osteoblast-like cells were able to adhere and spread on less soluble and more stable crystalline phase surfaces. ${ }^{54,55}$ Thus, compared with BCP substrates, the nHA-coated BCP scaffolds resulted in better bioactivity. However, it was difficult to perform a statistical analysis of new bone production, as previous studies suggest that materialinduced osteogenesis is species-dependent and ectopic bone formation in rabbits is relatively poor. ${ }^{33,56,57}$ However, the presence of new bone 90 days post-implantation suggested that the nHA-coated BCP scaffold with both trabecular bone-like architecture and a nanostructured surface might have good osteoinductive capacity. This should be further evaluated in future work using other animal models.

In summary, these findings indicate that the lack of integrity of BCP substrates had an adverse effect on osteogenesis, whereas the nHA-coated BCP scaffolds promoted osteogenic differentiation of BMSCs in vitro and induced ectopic bone formation in vivo (Figure 9), possibly owing to their multiscale porous structure and nanostructured surface. Previous porosimetry analyses showed that this biomimetic bone graft (nHA-coated BCP) has a graded pore gradient, including interconnected macropores $(\sim 700$ $\mu \mathrm{m})$ formed by matched replication of PU foam that promote vascularization and bone ingrowth, minorpores (20$50 \mu \mathrm{m})$ that facilitate cell migration, micropores $(0.8-3$ $\mu \mathrm{m})$ that accelerate nutrient exchange, ${ }^{23}$ and abundant nanopores $(<100 \mathrm{~nm})$ resulting from nanoparticle coating that stimulate osteointegration and osteogenesis; these nanopores were reported to have a positive effect on osteoregeneration during early implantation. ${ }^{6,58}$ Moreover, nHA-coated BCP scaffolds were shown to have a biomimetic nanostructured surface with abundant HA nanoparticles, similar to the inorganic component of natural bone, which was believed to promote tissue regeneration. ${ }^{42,43}$ Further research should focus on optimizing scaffold properties to achieve better osteoinductivity, including improving the mechanical behaviors and adjusting the degradation rate of the scaffold to match new bone growth, as well as expanding the use of nanostructured scaffolds to applications such as bone repair, drug delivery, and anti-tumor therapy.

\section{Conclusion}

Our current study provides a simple and effective strategy to construct biomimetic bone grafts with both trabecular framework and nano-scale topography by combining modified sponge replication and dip-coating technologies. The trabecular bone-like architecture favored tissue ingrowth and accelerated nutrient exchange, and the introduction of an HA nanoparticle layer endowed implants with nano-scale surface morphology, leading to enhanced osteogenesis via the BMP/Smad signaling pathway. These findings demonstrate that this biomimetic bone graft with a trabecular framework and nanostructured surface have potential clinical applications in bone defect regeneration. 


\section{Acknowledgments}

The authors thank Ms Jiao Lu, Ms Lingzhu Yu, and Mr Guolong Meng for their help with SEM measurements. This work was financially supported by the National Science Foundation of China (31670985, 31400819), the Sichuan Science and Technology Innovation Team of China (2019JDTD0008), and the "111" Project of China (B16033).

\section{Disclosure}

The authors report no conflicts of interest in this work.

\section{References}

1. Hong Y, Fan H, Li B, Guo B, Liu M, Zhang X. Fabrication, biological effects, and medical applications of calcium phosphate nanoceramics. Mater Sci Eng R Rep. 2010;70(3-6):225-242. doi:10.1016/ j.mser.2010.06.010

2. Tang Z, Tan Y, Ni Y, et al. Comparison of ectopic bone formation process induced by four calcium phosphate ceramics in mice. Mater Sci Eng C Mater Biol Appl. 2017;70:1000-1010. doi:10.1016/j. msec.2016.06.097

3. Yuan H, Fernandes H, Habibovic P, et al. Osteoinductive ceramics as a synthetic alternative to autologous bone grafting. Proc Natl Acad Sci USA. 2010;107(31):13614-13619. doi:10.1073/pnas.1003600107

4. Jones JR, Hench LL. Regeneration of trabecular bone using porous ceramics. Curr Opin Solid State Mater Sci. 2003;7(4-5):301-307. doi:10.1016/j.cossms.2003.09.012

5. Habibovic P, Sees TM, van Den Doel MA, et al. Osteoinduction by biomaterials - physicochemical and structural influences. $J$ Biomed Mater Res Part A. 2006;77A(4):747-762.

6. Bohner M, Baroud G, Bernstein A, et al. Characterization and distribution of mechanically competent mineralized tissue in micropores of $\beta$-tricalcium phosphate bone substitutes. Mater Today. 2017;20(3):106-115.

7. Bose S, Tarafder S. Calcium phosphate ceramic systems in growth factor and drug delivery for bone tissue engineering: a review. Acta Biomater. 2012;8(4):1401-1421.

8. Wang W, Itoh S, Tanaka Y, et al. Comparison of enhancement of bone ingrowth into hydroxyapatite ceramics with highly and poorly interconnected pores by electrical polarization. Acta Biomater. 2009;5(8):3132-3140.

9. Vats A, Tolley NS, Polak JM, Gough JE. Scaffolds and biomaterials for tissue engineering: a review of clinical applications. Clin Otolaryngol Allied Sci. 2010;28(3):165-172. doi:10.1046/j.13652273.2003.00686.x

10. Utara S, Klinkaewnarong J. Sonochemical synthesis of nano-hydroxyapatite using natural rubber latex as a templating agent. Ceram Int. 2015;41(10):14860-14867. doi:10.1016/j.ceramint.2015.08.018

11. Su Y, Komasa S, Li P, et al. Synergistic effect of nanotopography and bioactive ions on peri-implant bone response. Int $J$ Nanomed 2017;12:925-934. doi:10.2147/IJN.S126248

12. Wang D-X, He Y, Bi L, et al. Enhancing the bioactivity of Poly (lactic-co-glycolic acid) scaffold with a nano-hydroxyapatite coating for the treatment of segmental bone defect in a rabbit model. Int $J$ Nanomed. 2013;8:1855-1865.

13. Cai Y, Liu Y, Yan W, et al. Role of hydroxyapatite nanoparticle size in bone cell proliferation. $J$ Mater Chem. 2007;17(36):3780. doi:10.1039/b705129h
14. Jiang L, Li Y, Xiong C, Su S, Ding H. Preparation and properties of bamboo fiber/nano-hydroxyapatite/poly(lactic-co-glycolic) composite scaffold for bone tissue engineering. ACS Appl Mater Interfaces. 2017;9(5):4890-4897. doi:10.1021/acsami.6b15032

15. Teotia AK, Raina DB, Singh C, et al. Nano-hydroxyapatite bone substitute functionalized with bone active molecules for enhanced cranial bone regeneration. ACS Appl Mater Interfaces. 2017;9(8):6816-6828.

16. Remya NS, Syama S, Gayathri V, Varma HK, Mohanan PV. An in vitro study on the interaction of hydroxyapatite nanoparticles and bone marrow mesenchymal stem cells for assessing the toxicological behaviour. Colloids Surf B Biointerfaces. 2014;117:389-397. doi:10.1016/j.colsurfb.2014.02.004

17. Nie W, Peng C, Zhou X, et al. Three-dimensional porous scaffold by self-assembly of reduced graphene oxide and nano-hydroxyapatite composites for bone tissue engineering. Carbon. 2017;116:325-337. doi:10.1016/j.carbon.2017.02.013

18. Sun Y, Chen Y, Ma X, et al. Mitochondria-targeted hydroxyapatite nanoparticles for selective growth inhibition of lung cancer in vitro and in vivo. ACS Appl Mater Interfaces. 2016;8(39):25680-25690. doi:10.1021/acsami.6b06094

19. Wu H, Li Z, Tang J, et al. The in vitro and in vivo anti-melanoma effects of hydroxyapatite nanoparticles: influences of material factors. Int J Nanomed. 2019;14:1177-1191. doi:10.2147/IJN.S184792

20. Ionita $D$, Bajenaru-Georgescu $D$, Totea G, et al. Activity of vancomycin release from bioinspired coatings of hydroxyapatite or $\mathrm{TiO} 2$ nanotubes. Int J Pharm. 2017;517(1-2):296-302. doi:10.1016/j.ijpharm.20 16.11.062

21. Liu S, Li H, Su Y, Guo Q, Zhang L. Preparation and properties of in-situ growth of carbon nanotubes reinforced hydroxyapatite coating for carbon/carbon composites. Mater Sci Eng C Mater Biol Appl. 2017;70:805-811. doi:10.1016/j.msec.2016.09.060

22. Xiao Y, Gong T, Zhou S. The functionalization of multi-walled carbon nanotubes by in situ deposition of hydroxyapatite. Biomaterials. 2010;31 (19):5182-5190. doi:10.1016/j.biomaterials.2010.03.012

23. Wang J, Zhu Y, Wang M, et al. Fabrication and preliminary biological evaluation of a highly porous biphasic calcium phosphate scaffold with nano-hydroxyapatite surface coating. Ceram Int. 2018;44 (2):1304-1311. doi:10.1016/j.ceramint.2017.08.053

24. Qing F, Wang Z, Hong Y, et al. Selective effects of hydroxyapatite nanoparticles on osteosarcoma cells and osteoblasts. J Mater Sci Mater Med. 2012;23(9):2245-2251. doi:10.1007/s10856-012-4703-6

25. Tang Z, Li X, Tan Y, Fan H, Zhang X. The material and biological characteristics of osteoinductive calcium phosphate ceramics. Regen Biomater. 2018;5(1):43-59. doi:10.1093/rb/rbx024

26. Ebrahimi M, Botelho MG, Dorozhkin SV. Biphasic calcium phosphates bioceramics (HA/TCP): concept, physicochemical properties and the impact of standardization of study protocols in biomaterials research. Mater Sci Eng C Mater Biol Appl. 2017;71:1293-1312. doi:10.1016/j.msec.2016.11.039

27. Sadat-Shojai M, Khorasani MT, Dinpanah-Khoshdargi E, et al. Synthesis methods for nanosized hydroxyapatite with diverse structures. Acta Biomater. 2015;45(45):7591-7621.

28. Zhang L, Webster TJ. Nanotechnology and nanomaterials: promises for improved tissue regeneration. Nano Today. 2009;4(1):66-80. doi:10.1016/j.nantod.2008.10.014

29. Lin K, Xia L, Gan J, et al. Tailoring the nanostructured surfaces of hydroxyapatite bioceramics to promote protein adsorption, osteoblast growth, and osteogenic differentiation. ACS Appl Mater Interfaces. 2013;5(16):8008-8017. doi:10.1021/am402089w

30. Zhou H, Lee J. Nanoscale hydroxyapatite particles for bone tissue engineering. Acta Biomater. 2011;7(7):2769-2781. doi:10.1016/j. actbio.2011.03.019 
31. Castner DG, Ratner BD. Biomedical surface science: foundations to frontiers. Surf Sci. 2002;500(1-3):28-60. doi:10.1016/S0039-6028 (01)01587-4

32. Samavedi S, Whittington AR, Goldstein AS. Calcium phosphate ceramics in bone tissue engineering: a review of properties and their influence on cell behavior. Acta Biomater. 2013;9(9):80378045. doi:10.1016/j.actbio.2013.06.014

33. Li B, Chen X, Guo B, Wang X, Fan H, Zhang X. Fabrication and cellular biocompatibility of porous carbonated biphasic calcium phosphate ceramics with a nanostructure. Acta Biomater. 2009;5 (1):134-143. doi:10.1016/j.actbio.2008.07.035

34. Gosain AK, Riordan PA, Song L, et al. A 1-year study of osteoinduction in hydroxyapatite-derived biomaterials in an adult sheep model: part II. Bioengineering implants to optimize bone replacement in reconstruction of cranial defects. Plast Reconstr Surg;2004:11551163. doi:10.1097/01.PRS.0000135852.45465.A9

35. Nakashima K, Zhou X, Kunkel G, et al. The novel zinc fingercontaining transcription factor osterix is required for osteoblast differentiation and bone formation. Cell. 2002;108(1):17-29. doi:10.10 16/s0092-8674(01)00622-5

36. Klein A, Baranowski A, Ritz U, et al. Effect of bone sialoprotein coated three-dimensional printed calcium phosphate scaffolds on primary human osteoblasts. J Biomed Mater Res B Appl Biomater. 2018;106(7):2565-2575. doi:10.1002/jbm.b.34073

37. Lee WH, Loo CY, Rohanizadeh R. A review of chemical surface modification of bioceramics: effects on protein adsorption and cellular response. Colloids Surf B Biointerfaces. 2014;122:823-834. doi:10.1016/j.colsurfb.2014.07.029

38. Xia L, Lin K, Jiang X, et al. Enhanced osteogenesis through nanostructured surface design of macroporous hydroxyapatite bioceramic scaffolds via activation of ERK and p38 MAPK signaling pathways. J Mater Chem B. 2013;1(40):5403. doi:10.1039/c3tb20945h

39. Liu Y, Bao C, Wismeijer D, Wu G. The physicochemical/biological properties of porous tantalum and the potential surface modification techniques to improve its clinical application in dental implantology. Mater Sci Eng C Mater Biol Appl. 2015;49:323-329. doi:10.1016/j. msec.2015.01.007

40. Mao L, Liu J, Zhao J, et al. Effect of micro-nano-hybrid structured hydroxyapatite bioceramics on osteogenic and cementogenic differentiation of human periodontal ligament stem cell via Wnt signaling pathway. Int J Nanomedicine. 2015;10:7031-7044. doi:10.2147/IJN. S90343

41. Nefussi JR, Brami G, Modrowski D, Oboeuf M, Forest N. Sequential expression of bone matrix proteins during rat calvaria osteoblast differentiation and bone nodule formation in vitro. $J$ Histochem Cytochem. 1997;45(4):493-503. doi:10.1177/002215549704500402

42. Zhou C, Xie P, Chen Y, Fan Y, Tan Y, Zhang X. Synthesis, sintering and characterization of porous nano-structured $\mathrm{CaP}$ bioceramics prepared by a two-step sintering method. Ceram Int. 2015;41(3):46964705. doi:10.1016/j.ceramint.2014.12.018
43. Pilloni A, Pompa G, Saccucci M, et al. Analysis of human alveolar osteoblast behavior on a nano-hydroxyapatite substrate: an in vitro study. BMC Oral Health. 2014;14(1):22. doi:10.1186/1472-6831-14-90

44. Zhurong T, Zhe W, Fangzhu Q, et al. Bone morphogenetic protein Smads signaling in mesenchymal stem cells affected by osteoinductive calcium phosphate ceramics. J Biomed Mater Res Part A. 2015;103(3):1001-1010. doi:10.1002/jbm.a.35242

45. Wan M, Cao X. BMP signaling in skeletal development. Biochem Biophys Res Commun. 2005;328(3):651-657. doi:10.1016/j.bbrc.20 04.11.067

46. Yang J, Shi P, Tu M, et al. Bone morphogenetic proteins: relationship between molecular structure and their osteogenic activity. Food Sci Human Wellness. 2014;3(3-4):127-135. doi:10.1016/j.fshw.2014.12.002

47. Jo IH, Shin KH, Soon YM, et al. Highly porous hydroxyapatite scaffolds with elongated pores using stretched polymeric sponges as novel template. Mater Lett. 2009;63(20):1702-1704.

48. Renghini C, Komlev V, Fiori F, et al. Micro-CT studies on 3-D bioactive glass-ceramic scaffolds for bone regeneration. Acta Biomater. 2009;5(4):1328-1337.

49. Passuti N, Daculsi G, Rogez JM, et al. Macroporous calcium phosphate ceramic performance in human spine fusion. Clin Orthop Relat Res. 1989;248:169-176.

50. Barrere F, van Blitterswijk CA, de Groot K. Bone regeneration: molecular and cellular interactions with calcium phosphate ceramics. Int J Nanomed. 2006;1(3):317-332.

51. Nich C, Goodman SB. The role of macrophages in the biological reaction to wear debris from joint replacements. J Long Term Eff Med Implants. 2014;24(4):259-265.

52. Nich C, Takakubo Y, Pajarinen J, et al. Macrophages - key cells in the response to wear debris from joint replacements. J Biomed Mater Res Part A. 2013;101(10):3033-3045.

53. John A, Varma HK, Kumari TV. Surface reactivity of calcium phosphate based ceramics in a cell culture system. J Biomater Appl. 2003;18(1):63-78.

54. Berube P, Yang Y, Carnes DL, et al. The effect of sputtered calcium phosphate coatings of different crystallinity on osteoblast differentiation. J Periodontol. 2005;76(10):1697-1709.

55. Hu Q, Tan Z, Liu Y, et al. Effect of crystallinity of calcium phosphate nanoparticles on adhesion, proliferation, and differentiation of bone marrow mesenchymal stem cells. J Mater Chem. 2007;17(44):46904698.

56. Habibovic P, de Groot K. Osteoinductive biomaterials - properties and relevance in bone repair. J Tissue Eng Regen Med. 2007;1 (1):25-32.

57. Yang Z, Yuan H, Tong W, et al. Osteogenesis in extraskeletally implanted porous calcium phosphate ceramics: variability among different kinds of animals. Biomaterials. 1996;17:2131-2137.

58. Rustom LE, Boudou T, Lou S, et al. Micropore-induced capillarity enhances bone distribution in vivo in biphasic calcium phosphate scaffolds. Acta Biomater. 2016;44:144-154.
International Journal of Nanomedicine

\section{Publish your work in this journal}

The International Journal of Nanomedicine is an international, peerreviewed journal focusing on the application of nanotechnology in diagnostics, therapeutics, and drug delivery systems throughout the biomedical field. This journal is indexed on PubMed Central, MedLine, CAS, SciSearch ${ }^{\mathbb{B}}$, Current Contents ${ }^{\mathbb{B}} /$ Clinical Medicine, $^{2}$
Journal Citation Reports/Science Edition, EMBase, Scopus and the Elsevier Bibliographic databases. The manuscript management system is completely online and includes a very quick and fair peer-review system, which is all easy to use. Visit http://www.dovepress.com/ testimonials.php to read real quotes from published authors. 